\title{
Editorial
}

\section{Botulinum Toxins for Analgesia}

Howard S. Smith, MD

In a landmark article in Annals of Neurology, Ranoux et al (1) have convincingly demonstrated that botulinum toxin type A (BTX-A) may provide direct analgesic effects in patients with focal chronic neuropathic pain independent of its effects on muscle tone. Ranoux and colleagues (1) appropriately point out that large-scale studies are needed to confirm the results and to determine whether BTX-A may also be effective in other forms of neuropathic pain. However, in spite of a relatively small number of patients, Dr. Murinson (2) accurately reports that Ranoux et al provide Class I evidence in support of an effective new approach to the treatment of focal neuropathic pain.

Preclinical evidence exists supporting the antinociceptive qualities of BTX-A (3). Subcutaneous (s.c.) BTX$A$ also inhibits inflammatory pain in the rat formalin model, and the present study examined whether this could be due to a direct action on sensory neurons (3). BTX-A (3.5-30 U/kg) was injected s.c. into the subplantar surface of the rat hind paw followed 1-5 days later by $50 \mathrm{~mL}$ of $5 \%$ formalin. Using microdialysis, it has been shown that BTX-A significantly inhibited formalin-induced glutamate release (peak inhibitions: $35 \%$, $41 \%$, and $45 \%$ with $3.4,7$, and $15 \mathrm{U} / \mathrm{kg}$ respectively) (3). BTX-A also dosed dependently reduced the number if formalin-induced Fos-like immunoreative cells in the dorsal horn of the spinal cord and significantly (15 and $30 \mathrm{U} / \mathrm{kg}$ ) inhibited the excitation of wide dynamic range neurons of the dorsal horn in Phase II but not Phase I of the formalin response. These results indicate that s.c. BTX-A inhibits neurotransmitter release from primary sensory neurons in the rat formalin model (3). Through this mechanism, BTX-A inhibits peripheral sensitization in these models, which leads to an indirect reduction in central sensitization (3).

Early in the use of BTX-A for dystonia, some au- thors noted that pain relief preceded muscle decontraction and exceeded what would have been expected solely as a consequence of muscle relaxation (3). These findings suggested that BTX-A might have analgesic properties independent of its myorelaxant action. Further information came from in vitro experiments demonstrating that BTX-A could inhibit neurogenic inflammation, a process that results from the sensitization of C-fiber nociceptors (4). The effects of BTX-A involved attenuation of the release of neurotransmitters including substance $P(5,6)$, calcitonin gene*related peptide $(7,8)$, and glutamate (9), and inhibition of vanilloid receptor activity (10). Consistent with these in vitro experiments, peripheral injections of BTX-A reduces nociceptive behaviors in animal models of inflammatory $(9,11)$ and traumatic neuropathic pain (12-14).

The efficacy of BTX-A in neuropathic pain has been suggested only in small anecdotal case reports (15-18). In this study, Ranoux and colleagues investigated for the first time the potential direct analgesic effects of one-time BTX-A in the painful area in patients with focal neuropathic pain (e.g., posttraumatic/postoperative pain or postherpetic neuralgia)

From: Albany Medical College Department of Anesthesiology, Albany, NY.

Dr. Smith is Editor-in-Chief of the Pain Physician journal and Associate Professor and Academic Director of Pain Management for Albany Medical College Department of Anesthesiology, Albany, NY.

Address correspondence: Howard S. Smith, MD Academic Director of Pain Management Albany Medical College Department of Anesthesiology 47 New Scotland Avenue; MC-131 Albany, New York 12208

E-mail: smithh@mail.amc.edu 
associated with allodynia using a double-blind, placebo-controlled parallel group design (1). The injections were performed intradermally to exclude effects on muscle tone (1).

Twenty-nine patients received a one-time intradermal administration of BTX-A (20 - 190 units) into the painful area. Outcome measures, evaluated at baseline, then at 4, 12, and 24 weeks, included average spontaneous pain intensity, quantified testing of thermal and mechanical perception and pain, allodynia to brushing (area, intensity), neuropathic symptoms, clinical global impression, and quality of life (1).

Treatment was administered by a neurologist not involved in the assessment. Aliquots of $100 \mathrm{U} / \mathrm{vial}$ BTXA were reconstituted with $4 \mathrm{ml}$ nonpreserved saline solution $(0.9 \%)$ as recommended by the manufacturer (concentration of 5 units BTX-A/0.2 mL, and placebo consisted of an equal volume of saline $[9 \% \mathrm{NaCl}]$. The injection of BTX-A or saline was performed according to a procedure adapted from that used for hyperhidrosis (19): BTX-A or placebo was injected intradermally into the skin $1.5 \mathrm{~cm}$ apart $(0.2 \mathrm{~mL}$, and thus 5 units of BTX-A per site) (1).

The primary outcome measure was self-reported average pain intensity from each morning's record in a diary concerning the last 24 hours using the 11-point numerical scale $(0=$ no pain; $10=$ maximal pain imaginable) of the Brief Pain Inventory $(1,20)$.

Sensory deficits and pain were measured and assessed by the same investigator at baseline, and after 4 and 12 weeks, as in prior therapeutic trials $(21,22)$. Brush-induced allodynia was evaluated by stroking the skin with a standardized brush (Senselab brush-0.5; Somedic AB, Horby, Sweden) and was considered as present if this evoked a clear sensation of pain. The intensity of allodynia (recorded on a $100 \mathrm{~mm}$ visual analog scale) and its area (traced on a transparent paper, then digitized for measurement on Canvas 6.0 software) were measured. Mechanical sensations (detection thresholds to nonpainful stimuli) and pain thresholds were measured with calibrated von Frey hairs $(0.06$ - 300gm) (Somedic $A B$, Sweden). Thermal sensations and pain thresholds (in ${ }^{\circ} \mathrm{C}$ ) were assessed with a Somedic thermotest (Somedic $A B$ ) by the method of limits, with baseline temperatures adjusted to the patient's skin temperature according to a procedure largely described elsewhere (23). Measurements obtained in the area of maximal pain were compared with those of the homologous contralateral side (1).

Other secondary outcome measures (completed at baseline and follow-up visits) included a visual analog scale rating the average pain over the last 24 hours on a $100 \mathrm{~mm}$ line; the neuropathic pain symptom inventory (24) rating the mean intensity of 10 neuropathic symptoms and their combination into 5 distinct dimensions during the last 24 hours on 11-point ( $0-10$ points) numerical scales, the duration of spontaneous pain and number of pain paroxysms (assessed with the neuropathic pain symptom inventory on categorical scales), 6 of 7 items for pain interference of the Brief Pain Inventory (with the exclusion of the item "ability to walk" judged irrelevant here) rated from 0 (does not interfere) to 10 (complete interference), the Hospital Anxiety and Depression Scale (25) including 14 items scored as anxiety and depression scores (each on 21), subjective pain relief because of the treatment over the past week (from $0 \%$ [no pain relief] to $100 \%$ [maximal pain relief]), the patients' overall impression of change on a 7-point scale (from very much improved to very much worse), and the assessment of blindedness (1).

BTX-A treatment, relative to placebo, was associated with persistent effects on spontaneous pain intensity from 2 weeks after the injection to 14 weeks. These effects correlated with the preservation of thermal sensation at baseline $(p<0.05)$. BTX-A also improved allodynia to brush and decreased pain thresholds to cold, without affecting perception thresholds. There were sustained improvements in the proportion of responders (number needed to treat for $50 \%$ pain relief: 3.03 at 12 weeks), neuropathic symptoms, and general activity. Most patients reported pain during the injections, but there were no further local or systemic side effects (1).

Ranoux and colleagues concluded that BTX-A may induce direct analgesic effects in patients with chronic neuropathic pain independent of its effects on muscle tone (1). The treatment of postherpetic neuralgia and painful focal neuropathies with BTX-A offers several distinct benefits compared with existing treatment options, including that it is reasonably safe, effective, long-lasting, and potentially free from cognitive side effects (2). 


\section{References}

1. Ranoux D, Attal N, Morain F, Bouhassira D. Botulinum toxin type a induces direct analgesic effects in chronic neuropathic pain. Ann Neurol 2008; 64:274-284.

2. Murinson B. Botulinum toxin type a treatment of painful focal neuropathies: new evidence for efference of afferents. Ann Neurol 2008; 64:236-238.

3. Aoki KR. Review of a proposed mechanism for the antinociceptive action of botulinum toxin type A. Neurotoxicology $2005 ; 26: 785-793$.

4. Handwerker HO. Nociceptors: Neurogenic inflammation. In: Cervero $\mathrm{F}$, Jensen TS (eds). Pain: Handbook of clinical neurology. Vol 81. Elsevier, Amsterdam, 2006, pp 23-33.

5. Ishikawa $\mathrm{H}$, Mitsui $\mathrm{Y}$, Yoshitomi T, Mashimo K, Aoki S, Mukuno K, Shimizu K. Presynaptic effects of botulinum toxin type A on the neuronally evoked response of albino and pigmented rabbit iris sphincter and dilator muscles. Jpn J Ophthalmol 2000; 44:106 -109.

6. Purkiss J, Welch M, Doward S, Foster K. Capsaïcin-stimulated release of substance $P$ from cultured dorsal root ganglion neurons: involvement of two distinct mechanisms. Biochem Pharmacol 2000; 59:1403-1406.

7. Meunier FA, Colasante C, Faille L, Gastard M, Molgó J. Upregulation of calcitonin gene related peptide at mouse motor nerve terminals poisoned with botulinum type-A toxin. Pflugers Arch 1996; 431(suppl 2):R297-R298.

8. Durham PL, Cady R, Cady R. Regulation of calcitonin generelated peptide secretion from trigeminal nerve cells by botulinum toxin type A: implications for migraine therapy. Headache 2004 ; 44:35- 42 .
9. Cui M, Khanijou S, Rubino J, Aoki KR. Subcutaneous administration of botulinum toxin A reduces formalin-induced pain. Pain 2004; 107:125-133.

10. Morenilla-Palao C, Planells-Cases R, Garcia-Sanz N, Ferrer-Montiel A. Regulated exocytosis contributes to protein kinase $C$ potentiation of vanilloid receptor activity. J Biol Chem 2004; 279:25665-25672.

11. Luvisetto S, Marinelli S, Lucchetti F, Marchi F, Cobianchi S, Rossetto O, Montecucco C, Pavone F. Botulinum neurotoxins and formalin-induced pain: Central vs. peripheral effects in mice. Brain Res 2006; 1082:124-131.

12. Bach-Rojecky L, Relja M, Lackovic Z. Botulinum toxin type $A$ in experimental neuropathic pain. J Neural Transm 2005; 112:215-219.

13. Luvisetto S, Marinelli S, Cobianchi S, Pavone F. Anti-allodynic efficacy of botulinum neurotoxin $A$ in a model of neuropathic pain. Neuroscience 2007; 145:1- 4 .

14. Park HJ, Lee Y, Lee J, Park C, Moon DE. The effects of botulinum toxin $A$ on mechanical and cold allodynia in a rat model of neuropathic pain. Can J Anesth 2006; 53:470-477.

15. Argoff CE. A focused review on the use of botulinum toxins for neuropathic pain. Clin J Pain 2002; 18:S177-S181.

16. Freund B, Schwartz M. Subcutaneous BTX-A in the treatment of neuropathic pain: A pilot study. Presented at 38th Interagency Botulism Research Coordinating Meeting; October 17-19, 2001; Easton, MD.

17. Jabbari B, Maher N, Difazio MP. Botulinum toxin $A$ improved burning pain and allodynia in two patients with spinal cord pathology. Pain Med 2003; 4:206 210.

18. Liu HT, Tsai SK, Kao MC, Hu JS. Botulinum toxin $A$ relieved neuropathic pain in a case of post-herpetic neuralgia. Pain Med 2006; 7:89 -91.

19. Naumann M, Flachenecker P, Bröcker EB, Toyka KV, Reiners K. Botulinum toxin for palmar hyperhidrosis. Lancet 1997; 349:252.

20. Cleeland CS, Ryan KM. Pain assessment: Global use of the Brief Pain Inventory. Ann Acad Med Singapore 1994; 23:129-138.

21. Wallace MS, Rowbotham MC, Katz NP, Dworkin RH, Dotson RM, Galer BS, Rauck RL, Backonja MM, Quessy SN, Meisner PD, A randomized, doubleblind, placebo-controlled trial of a glycine antagonist in neuropathic pain. Neurology 2002; 59:1694-1700.

22. Attal N, Rouaud J, Brasseur L, Chauvin M, Bouhassira D. Systemic lidocaine in pain due to peripheral nerve injury and predictors of response. Neurology 2004; 62:218-225.

23. Ducreux D, Attal N, Parker F, Bouhassira D. Mechanisms of central neuropathic pain: A combined psychophysical and fMRI study in syringomyelia. Brain 2006; 129:963-976.

24. Bouhassira D, Attal N, Fermanian J, Alchaar H, Gautron M, Masquelier E, Rostaing S, Lanteri-Minet M, Collin E, Grisart J, Boureau F. Development and validation of the Neuropathic Pain Symptom Inventory. Pain 2004; 108:248 257.

25. Zigmond AS, Snaith RP. The hospital anxiety and depression scale. Acta Psychiatr Scand 1983; 67:361-370. 
